\title{
Elderly South Asians in Britain: A survey of relevant literature and themes for future research
}

\author{
NICHOLAS MAYS*
}

\section{ABSTRACT}

The number of elderly Commonwealth South Asian immigrants in Britain originating from the Indian sub-continent will grow substantially in the next few years, yet there has been little consideration of this group in terms of academic social research. Indeed, welfare agencies are only beginning to become aware of the possible needs of this group. A survey of the scanty British literature on elderly ethnic minorities reveals the paucity of existing knowledge. However, studies from other countries, notably Japan and the U.S.A., suggest a number of illuminating areas for research. The presence of a culturally distinct Asian ethnic minority group experiencing ageing in British conditions appears to afford a good opportunity to throw further light on an important aspect of gerontological theory: namely the respective weight to be attached to cultural factors, social structure and the degree of societal modernisation in shaping the ageing process of individuals and groups.

The literature which exists on elderly people from ethnic minorities in Britain is slender and focuses most often on the practical problems which the elderly of South Asian and Afro-Caribbean ethnic groups face. ${ }^{1-4}$ A wide range of potential, social, financial, medical, psychological and communication problems has been raised, but 'no-one has yet demonstrated whether such problems are widespread among ethnic minority elderly, or whether community workers are dealing with an unfortunate few'. ${ }^{5}$ However, in the last two years, three pieces of research have been published which begin to remedy the dearth of factual knowledge. They provide the basis for more sophisticated work to clarify the complex interaction of Asian cultures, with their respect

* Research Officer, Research Unit, The Sports Council, I6 Upper Woburn Place, London WC:H oQP; formerly Department of Community Health, University of Leicester, School of Medicine. 
for the aged, membership of a minority group, place of origin, date of migration, life history, social class and other factors in defining the position in British society and problems of the South Asian elderly who came to Britain as immigrants from the New Commonwealth and Pakistan in the post-war period. ${ }^{6-8}$

For a long time the specific needs of elderly Asians have been ignored or played down for a variety of reasons, such as the glib assumption that Asian families all care for their elderly in such a way that outside intervention or special consideration is unnecessary; or because they have made few demands on services; or because of an integrationist philosophy not uncommon among welfare workers. In an unpublished discussion paper to the National Institute for Social Work, John Bland reports that he came across...'puzzlement that there could be a problem'... from central government departments, the caring professions and voluntary organisations. ${ }^{9}$ By contrast, those who began to consider the needs of elderly Asians tended to take a most gloomy view, stressing the problems and difficulties of this group to the exclusion of almost everything else. ${ }^{10}$ At the same time, the existing gerontological literature which addresses itself to issues of culture and ethnicity in ageing has only a heavily qualified relevance to the British context of elderly Asian migrants. The studies on the broad theme of ageing and modernisation which have attempted to trace the impact of the development of modern industrial society on the experience of growing old have mostly been cross-cultural comparisons between societies at different stages of modernisation, ${ }^{11}$ or studies of ageing in relatively ethnically homogeneous societies undergoing a process of modernisation, rather than studies of recent migrants. The bulk of the literature on ageing and ethnicity comes from the U.S.A. and refers in the main to longstanding ethnic minorities. ${ }^{12}$ Despite this, an attempt will be made to relate the existing British literature on elderly Asian immigrants to such work. The coverage is not intended to be exhaustive: topics such as the detail of the domestic and family processes in Asian families, inter-generational support systems and gender differences in ageing cross-culturally are not thoroughly explored, partly because of lack of space and partly because relevant literature is not always available. Inevitably too, in a field where the literature is scanty, evidence from studies of non-Asian elderly minorities has been analysed where it yields clues as to the ageing process among the Asian elders. This is not to imply that careful distinctions should not be made both between and within ethnic groups in their experience of ageing where possible.

Before this, it is important to depict briefly the circumstances of Asian 
elders in Britain. They represent a heterogeneous group, the product of a series of migrations of differing size, origin, and composition over the last fifty years, which began between the wars and extended into the I 970 with refugees from East Africa.

Often faced with discrimination and racism, migrants took steps to maintain their culture as a functional coping mechanism and to ensure its transmission and in many cases retained a belief in return to their homeland. ${ }^{13,14}$ Evidence from other countries appears to show that cultural differences of family structure and patterns of ageing are not easily erased by migration into a Western country from the East. ${ }^{15}$ It would appear that elderly Asians continue to rely on the Asian communities almost exclusively for social contact, social acceptance, and social support. It cannot be assumed in advance that the cultural distinctiveness of the ageing experience of today's Asian elderly will cease to have force in the future.

\section{Ethnicity and Ageing: The 'Double Jeopardy' and 'Age-as-Leveller' Hypotheses}

Despite limitations in its applicability to Britain, the American evidence on ethnicity and ageing has the value of suggesting, firstly, some of the aspects of ageing between ethnic minorities and majority populations which may potentially yield significant differences in Britain; secondly, that the mere passage of time cannot be assumed to minimise differences in life chances and life styles between different ethnic groups; ${ }^{16,17}$ thirdly, that the situation of the ethnic minority elderly is likely to be the product of the accumulated experiences and problems of a lifetime of membership of a minority group, as well as the current experience of problems associated with old age. ${ }^{18,19}$

The minority aged are said to bear a double burden. Like other older people in industrial societies they experience the devaluation of old age found in most modern societies. ${ }^{20}$ 'Unlike other older people however, the minority aged must bear the additional economic, social and psychological burdens of living in a society in which racial equality remains more myth than social policy. ${ }^{21}$ On the other hand, according to the 'age-as-leveller' thesis, variant sub-cultures may prove coping structures to support their aged members, ${ }^{22-24}$ though old people may remain ignorant of services, ${ }^{25}$ and minority elderly are said to be able to draw on resources developed in a lifetime of facing up to disadvantage. Evidence shows, for example that older Blacks and Mexican Americans 
have a higher level of interaction with children and relatives than whites ${ }^{26,27}$ and seemingly more supportive families. ${ }^{28,}{ }^{29}$ Kiefer notes the 'structural intimacy' based on social networks and cultural values of ethnic sub-cultures. ${ }^{30}$ This may have important implications for the self-esteem of elderly members of ethnic minorities, since the argument is that the elderly will be assigned worth as part of the ethnic group rather than devalued as no longer productive. The elderly may play a major role where a minority wishes to preserve its cultural roots. ${ }^{31-33}$ Moore, however, points to a tendency of white researchers in the U.S.A. to romanticize 'folk societies' and to confuse... 'normative statements of group members about what ought to be the relations between family members and behavioural observations about what actually prevails' ${ }^{34}$ Faced with life in Britain the level and quality of social networks and family support and status of the Asian elderly will contribute significantly to their quality of life, yet similar problems of research face the outsider who tries to disentangle norms from reality in the Asian community in Britain.

\section{The British Literature on Elderly Ethnic Minorities ${ }^{35}$}

The British equivalent of 'double jeopardy' was not explicitly stated until as late as 1974: the first discussion of elderly ethnic minorities to distinguish between problems shared with the white elderly and those to which the black elderly were particularly at risk appeared in that year. ${ }^{35}$ It is inevitable with a small body of research that the discussion will be in very general terms, obscuring the variety of culture, background, social status and recent history present in the Asian population in Britain. There is also a difficulty in that part of the evidence cited relates to West Indian elderly. While there is no intention to lump Asians and West Indians together indiscriminately, since different groups will have differing cultural resources and social networks to draw on and will care for their elderly in different ways, certain of the findings on West Indian elders hint at the situation of Asian elders and are included for this reason.

According to the 1971 Census, still the basis for official U.K. estimates of the black population, until data from the 198 I Census appear, there were 18,000 New Commonwealth and Pakistani (NCWP) people over sixty-five years of age in Great Britain, which was $1.3 \%$ of the total NCWP population (see Table I). ${ }^{36}$ In Table $\mathrm{I}$, the 1976 estimate for the NCWP population shows 32 ,ooo over- 65 s, which was about $2 \%$ of the total NCWP population, and a middle-aged group (45-64 years of 
TABLE I. Population of New Commonwealth and Pakistani ethnic origin in Great Britain: age structure

\begin{tabular}{ccccc}
\hline Age groups (years) & \multicolumn{2}{c}{$\begin{array}{c}\text { I97I } \\
\text { (thousands) }\end{array}$} & $\begin{array}{c}\text { I976 } \\
\text { (percentages) }\end{array}$ \\
\hline $0-4$ & 217 & 236 & 15.8 & 13.3 \\
$5^{-14}$ & $34^{2}$ & $44^{8}$ & 24.9 & 25.3 \\
$15^{-24}$ & 233 & 353 & 17 & 19.9 \\
$25-44$ & 439 & 509 & 32 & 28.8 \\
$45^{-64}$ & 122 & 193 & 8.9 & 10.9 \\
$65+$ & 18 & 32 & 1.3 & 1.8 \\
Total population & 1,37 I & $1,77^{2}$ & 100 & 100 \\
\hline
\end{tabular}

Source: Central Statistical Office, Social Trends, 9 (1979), 69 (adapted).

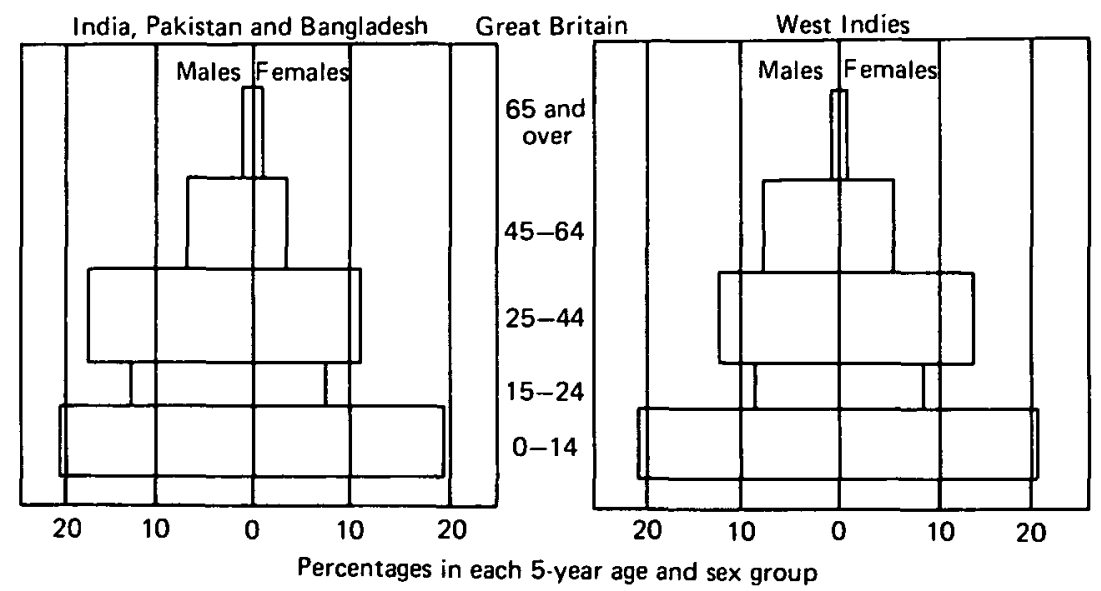

Figure 1. Age and sex structure of populations originating from India, Pakistan and Bangladesh, and from the West Indies, 1976. Source: Central Statistical Office, Social Trends, 9 (1979), 70.

age) of 193,000 or I I \% of the total. ${ }^{37}$ It is probable that somewhat over half the 32,000 over- 65 s estimated in 1976 were Asian, say about 18,000 , but it is important to note that those in middle age in 1976 represented a far larger proportion of the Asian population than the over- 655 , as Figure I shows. ${ }^{38}$ It seems that the number of elderly will increase appreciably in the future as the age distribution of the NCWP population comes more closely to resemble that of the rest of the population. Furthermore, those who are still middle-aged may already be facing a number of the problems more usually associated with older age groups, as redundancy and early retirement become more common.

Projections show the elderly NCWP population rising by $136 \%$ from 


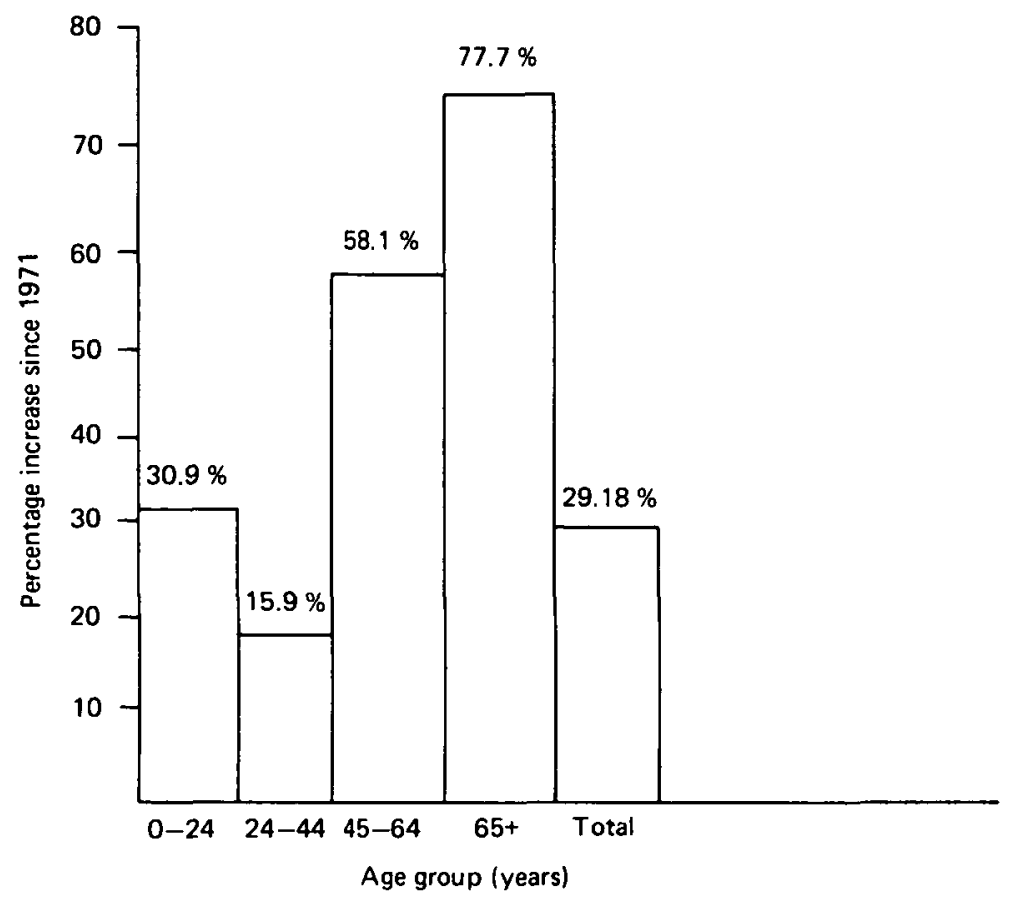

Figure 2. Population of New Commonwealth and Pakistan ethnic origin: percentage increase 1971-6. Source: Central Statistical Office, Social Trends, 9 (1979), 69 (adapted).

31,000 in 1976 to 73,000 in $199^{139}{ }^{39}$ The over-45s will have doubled in the ten years $1976-86$. Figure 2 shows that in the five years 197 I-6 the elderly rose by $78 \%$, which was the biggest growth in any age group in the NCWP population. ${ }^{40}$

Although numerically and as a proportion of the total U.K. elderly population the Asian and Afro-Caribbean elderly could be deemed insignificant, the national statistics conceal some evidence at local level of sharp increases. Birmingham Community Relations Council estimated that the NCWP elderly would double every seven years to the year 2000. ${ }^{41}$ However, accurate local data on numbers of Asian elderly do not appear to be available. In many areas data from the 197 I Census are worse than useless given the influx of Ugandan refugees in the interim. A Commission for Racial Equality (CRE) Working Party on Social Services Departments' response to a multi-racial society recommended local enumerations in 1978 . The report also said that 'Research should be initiated by the Department of Health and Social Security (DHSS) in collaboration with other bodies on ... elderly ethnic mino- 
rities, their needs and numbers' $\ldots{ }^{42}$ Recent evidence suggests that the report is little known in Social Services Department. ${ }^{43}$

Furthermore it cannot be assumed in advance that the numbers of elderly people will be substantially reduced by return to their countries of origin. Some, such as the Ugandan Asians, will find return especially difficult. Kippax found that only four people in his study of forty elderly West Indians in Lewisham had any 'realistic expectations' of going back home. ${ }^{44}$ Only $8 \%$ of elderly Asians in a recent survey had made any specific plans to return to their homelands. ${ }^{45}$

Hannon, drawing heavily on Lawrence, ${ }^{46}$ gives three main reasons for not returning: first, the journey may be financially impossible; secondly, although the money may be available, there is a reluctance to go home empty-handed; thirdly, the idea may never progress beyond a dream becauses the goals of migration are rarely sufficiently well defined for the migrant to know at a particular time that he has achieved what he set out to do. ${ }^{47}$ Other reasons for non-return are difficulties of transferring money and property overseas, emotional ties with relatives in Britain, British medical and social services, social change in the country of origin, the possibility that there may be no close kin or friends to care for the returning migrant and the psychological upheaval ofleaving a British home ${ }^{48}$ An interesting reason for non-return may be because 'Increasing reinforcement of cultural identity among ethnic communities after the first phase of migration, in particular among Asians, has stabilised their religious customs and norms which is likely to make old people feel reassured enough to live, be cared for and die in Britain' ${ }^{49}$ However, although the practicalities of return may be weighted against its occurrence, behaviour and attitudes may be profoundly affected by an intention, be it vague, to return, or even a strong sense of nostalgia for life before migration. It has been suggested that those who have the strongest desire to return home are those who are single or live alone. ${ }^{50}$

At the time of writing there have been only three notable studies of elderly members of ethnic minorities in Britain. The first is of West Indians in Leicester by Jo Cooper. ${ }^{51}$ It is a qualitative, in-depth study gained from a series of interviews (each partly structured) with sixteen elderly West Indians, all first-generation immigrants who had come to Britain in middle age and supplemented by visits to a number of statutory and voluntary agencies concerned with the elderly.

By contrast, the second study is a comparative community survey carried out in Birmingham in 1979 by a community group, AFFOR (All Faiths For One Race), of 400 Asian, Afro-Caribbean and white elders. ${ }^{52}$ 
The third study was a survey of 148 elderly and late-middle-aged West Indians in Nottingham, carried out by Nottinghamshire County Council Social Services Department with similar aims to the AFFOR study. ${ }^{53}$

Despite the tiny non-random group in Cooper's study, certain of her observations reinforce findings of the other two studies. Cooper found that the West Indians occupied positions of low economic status since they did not have occupational pensions or sources of income other than their state retirement pension or supplementary pension. Only one of the sixteen had worked long enough to have paid sufficient National Insurance contributions to be in receipt of a full retirement pension, something which affects the Asian elders even more severely. The rest were forced to rely on means-tested supplementary pension. The AFFOR and Nottingham findings reinforce this picture. Ninety-four per cent of the whites received state pensions as against only $46 \%$ of the Asians. There were about twice as many Asians and Afro-Caribbeans as whites in the lowest income bracket. ${ }^{54}$

Cooper's respondents had high expectations of the way in which their children should care for them. However, 'the links between grandparents and grandchildren did not seem to be as close as the West Indian tradition implies... the persons interviewed felt that the cause lay in the changing attitudes of the younger generation' ${ }^{55}$ This is something which could have major significance in association with cramped housing and necessity in determining whether or not elderly Asians are cared for within an extended family.

There is some limited evidence of changing attitudes to family patterns which needs to be tested more thoroughly. The Community Relations Commission study of relations between the generations revealed that $80 \%$ of the Asian parents and young people believed that 'Asians prefer to live as joint families', adducing reasons of tradition and pragmatic mutual aid..$^{56}$ On the other hand there was evidence of change in the future, since $57 \%$ of the children agreed that when they had a home of their own they would prefer to have only their husband/wife and children living with them. However, not all the evidence points to divergence between the generations. Recent anthropological studies have shown substantial cultural continuity between generations of Asians as younger people come to appreciate the norms of their parents and the instrumental value of the traditional patterns of family and community life when faced by racial hostility and discrimination. ${ }^{57}$ Thus, although the AFFOR study threw up the surprising and initially gloomy finding that $26 \%$ of the Asians claimed to have 'no family in Britain' and although this tended to throw doubt 
on the stereotype of the Asian elder invariably living in an extended family, the same study showed that only $5 \%$ of Asian elders lived alone, compared with $38 \%$ of white old people. Only ro $\%$ of the Asians lived with just one other person and $56 \%$ lived in households with between five and eight people. ${ }^{58}$ Of the West Indians in the Nottingham study, $18 \%$ were living as a single person in a household with others. ${ }^{59}$ This was three times the proportion in Hunt's national survey of the elderly. ${ }^{60}$ The vast majority of the Asians in the AFFOR sample were in daily contact with friends and relatives, although far more of the Asians than the other two groups reported not being able to occupy their time sufficiently. The Asians appeared still to be looked after, or to expect to be looked after, by immediate family and kin, in that almost one-third of the Asians volunteered the information that they would not need meals-on-wheels or a home help because their families would care for them. ${ }^{61}$ However, the risk that a small minority of the Asian elderly may suffer from acute isolation and/or deprivation cannot be ruled out. It was significant that most of those who lived alone in the AFFOR sample appeared to have no family in Britain.

Cooper's respondents had very little contact with whites. 'Only one of the persons interviewed had attended an English elderly persons' club and she had not enjoyed it'. ${ }^{62}$ Only $2 \%$ of the Asian sample in the AFFOR study were attending a day centre. ${ }^{63}$ Cooper's respondents appeared to have very little in common with the white elderly, except to share the same disadvantage of low income. In fact they felt that elderly whites were more hostile than younger people. The old people in Cooper's study did not feel able to use facilities such as day centres and clubs designed for the white elderly. Of the Asians in the AFFOR study who would have used day centres $25 \%$ did not do so because of worries about language difficulties. ${ }^{64}$

The published work of Jo Cooper, AFFOR and Nottinghamshire County Council is to be joined shortly by survey data from Age Concern England's study of 672 Black and Asian old people in Manchester and the Brent and Wandsworth areas of London. ${ }^{65}$ Since the first report of this important study is unpublished at the time of writing (October I 982 ), it is impossible to do more than sketch certain of the conclusions based on information from the author. In general, the Age Concern data on relationships with, uptake of, knowledge of and attitude to social and health services bear out the findings of the earlier studies which are discussed elsewhere in this article. However, the main theme of the Age Concern study, which was designed to obtain in-depth, qualitative and biographical data, is to show in detailed empirical terms the marked heterogeneity, previously conjectured, in the elderly in the Asian 
population. The most striking findings concern the differences between the successive cohorts of West Indian and Asian migrants on a wide variety of scores, as well as the disparities within each of the broad ethnic categories 'Asian' and 'West Indian' and the variety between those originating from different geographical and ethno-religious areas.

Jonathan Barker identifies four main groups of current black and Asian elderly.

I. 'Pioneers.' These are Asian men who came to Britain in the I930s and 1940 as seamen and salesmen and who are the oldest group today. They have very little wish for or contact with social services, leading isolated and fiercely independent lives.

2. 'Early migrants.' These are mostly men from very limited areas of India, and West Indian women, who came to Britain in the r95os to work in public services and industries such as textiles (in the North), with the aim of returning to their place of origin as people of substance. They are mainly aged 60-70 years today. Most of the AFFOR sample in Birmingham would fall into this group. In Barker's Manchester sample he found that many of the Asian men were living in a family with others, including the unmarried, who lived as 'uncles' with relatives. However, although respected as trail-blazers, they tended to be left out of the mainstream of family life and expressed regret and ambivalence at not being able to enjoy an old age as they conceived it to be in their homeland. In many ways their problems were similar to those of the white working class elderly in the same urban areas. One distinctive problem faced by this group was a lack of opportunities to meet people of the same age and sex from the same area of origin and sharing similar life histories.

3. 'Recent arrivals.' These are the parents and, in the Asian community, the wives of the early migrants. They came to Britain in the 1960 s to join their relatives and are mainly Asian. They comprise the bulk of the old elderly. In the case of the Asians, they are generally dependent on their children, have had no experience of work in Britain, have poor English, no pension entitlement and no role in the family since their children managed for a long period without them. Their particular problems were found to vary by ethnic sub-group.

4. 'Refugees.' In Barker's sample these were predominantly professional and managerial Asians, driven from East Africa in the late i 960 s and 1970 and forced to make a difficult and abrupt transition very late in life.

Attention is drawn by this sort of analysis to the importance of cohort and generational factors in shaping the lives of Asian elders and the conflicts they may be involved in. 
Overcrowding is often cited as a cause of tensions and disputes within Asian families and households. However, intergenerational tension may have other origins, most particularly in the uncertainty which tends to surround the status of elderly people in Asian families in Britain. Although the available literature does not begin to explore family processes in detail nor to describe gender differences in the status of the elderly, it would seem likely that elderly women continue to play an important role in the domestic economy despite the existence of frictions with daughters-in-law. The AFFOR study found that elderly Asian men were not nearly so home-centred as whites and Afro-Caribbeans and were reluctant to become involved in tasks which are commonly regarded as providing potentially important functions for them, such as looking after grandchildren. The men probably do not have the range of domestic skills to contribute to the domestic economy unless they are still in employment and able to contribute financially. This may make a severe dent in their self-esteem and traditional sense of authority. Attempts to re-assert their position may lead to conflict and disruption in the family.

A fruitful approach to understanding elderly Asian men and how they come to terms with such dislocations in their expectations of old age and consequent sense of loss may lie in Hazan's theoretical perspective on ageing, which defines the crucial problem for elderly people as reconciling what they want to do with what they are able to do. ${ }^{66}$ Hazan's study of mainly immigrant Jewish elders in a London day centre showed how a variety of coping strategies was devised by members, involving the construction of alternative realities which tended to eliminate from recall disruptive aspects of their previous lives and to focus on a present-oriented community life, in order to manage the increasing imbalance they experienced between the things they could control and those which were still meaningful but which were outside their personal control. Hazan's immigrant subjects had suffered loss, abandonment and various traumas associated with migration.

\section{Specific Problems from the Literature}

A number of specific problems which may face the Asian elderly are to be found in the literature. From the outline of the Age Concern study in the previous section, it is clear that different problems will affect different cohorts of elderly and to varying degrees. However, given the level of information available in published form, problems can only be discussed in very general terms. 
One of the most obvious, because of its service implications, is diet. A comparison of average Asian and indigenous British diets in 1974/5 concluded that the Asian diets had less satisfactory levels of energy, protein, calcium, iron, and vitamin $\mathrm{D}$, with the vegetarian Hindu diet the least satisfactory. ${ }^{67}$ However, not all dietary research has come to such clear-cut conclusions.

Providing suitable diets in hospitals, old peoples' homes and through the meals-on-wheels service is a related practical issue, since the elderly are likely to be the group least able to modify their dietary habits built up over a lifetime. Alien food adds to the stress of going into a strange environment such as a hospital, and may deter elderly people altogether ${ }^{68}$ Progress towards providing suitable diets in hospitals appears to be slow and patchy.

Another important problem area made more difficult by unfamiliarity with the British welfare system and fears about approaching officialdom, is the claiming of pensions, benefits and other allowances. Kippax found that over $25 \%$ of his respondents were receiving less than their full entitlement of financial benefits. Although respondents seemed better informed about cash benefits than welfare in kind, most of the $25 \%$ who were receiving less than their full entitlement were completely ignorant of any rights to cash benefits. ${ }^{69}$ This was an almost exclusively West Indian population of relatively long standing in Britain. By way of crude comparison, a recent survey of poverty in Britain showed $19.1 \%$ of the over-6os eligibile for supplementary pension but not claiming. ${ }^{70}$ The Asian elderly are probably even more reliant than other pensioners on supplementary pension with its complex claiming procedure. They will mostly have attained pensionable age before paying sufficient contributions to qualify for the full pension. ${ }^{11}$ A further problem which has been raised is that some Asians migrants had quoted an age lower than their real age on arrival in order to get employment and have thus found themselves unable to receive the benefits to which they are entitled chronologically until their 'official' age is sixty or sixty-five. ${ }^{72}$ Almost one-tenth of the Asians surveyed by AFFOR had encountered problems in trying to obtain a pension for these reasons. ${ }^{73}$ Furthermore, there are a considerable number of Asians (particularly from Uganda and Kenya) who are still below retirement age, but who have not been able to find work since arriving in Britain. ${ }^{74}$

The implications of the above for living standards are plain: the Asian elderly will generally tend to have low personal incomes. Their likely above-average dependence on supplementary benefit will mean that more of them live on or near the poverty line as assessed by their incomes, not to mention a significant group (we do not know how large) 
who came to Britain as dependents and who are thus ineligible for state pensions and supplementary benefits, and depend totally on the continuing goodwill of family, relatives and friends for support.

Housing is another aspect of the lives of the Asian elderly where it would seem that proper research into needs is urgently required. Trends towards the establishment of Asian households based on nuclear families and trends towards increasing numbers of old people left alone or rejected by their families are reported, but appear to be based on inference, anecdote and impressions. ${ }^{75-77}$ In the AFFOR study only a tiny proportion of Asian elders lived alone, and other data support this. ${ }^{78}$ However, we do not know accurately how family patterns are changing and what the demand will be for flats and sheltered housing for older Asians, or for council houses large enough to accommodate multi-generational families, so that the elderly can live with younger relatives. Changes may well be taking place which adversely affect the elderly. For instance, if a large family group is forced to live in cramped conditions because the housing available is unsuitable, it is conceivable that the elderly might suffer, surrendering living space to younger family members. There is indeed anecdotal evidence of elderly people, especially men, roaming the streets during the day in all weathers, apparently having been ejected from the house by their families, ${ }^{79}$ (it may well be, however that this phenomenon is no more than a derivation from an earlier pattern of outdoor leisure and socialising found in the Indian sub-continent), and of elderly Asians made homeless due to family tensions arising in a cramped house. Though it is not possible to say how typical such phenomena are, it is known that the Asian population generally lives in poorer housing that whites, ${ }^{80}$ and Haringey Community Relations Council, London, reckoned that many local Asian elders were inadequately housed. ${ }^{81}$

\section{Use of Welfare Services}

In general, it is safe to say that uptake of almost all services in kind is low. In $198 \mathrm{I}$ in the London borough of Haringey local authority lunch clubs catered for 900 elderly people of whom only 6 were West Indians and 5 Asians out of an estimated NCWP population of $4000 .^{82} \mathrm{~A}$ I 977 report on the needs of elderly Asians attributed low take-up to any one or a combination of the following factors.

' 1 . The elderly are being catered for adequately by the family.

2. (The) ... services are not geared towards meeting the needs of the elderly Asian population. 
3. The services are not known to them.

4. There may be a stigma attached to the provision.

5. The Social Services and voluntary organisations are not aware of the needs of the elderly Asian population.' ${ }^{33}$

The more recent AFFOR study shows quite clearly how much less aware of the various welfare services Asian elders, especially the women, are than either whites or Afro-Caribbeans. Sixty-four per cent of the Asians had no knowledge of and had never heard of a whole range of services from old people's homes to the home visting service, as against $3 \%$ of the Afro-Caribbeans and $2 \%$ of the Europeans. ${ }^{84}$

Kippax found that only $10 \%$ of his respondents attended any voluntary social clubs for the elderly, but $40 \%$ of the remainder said they would like to do so. ${ }^{85}$ Pyke-Lees and Gardiner, drawing on unpublished 197 I Census data on persons enunerated in homes for the elderly and disabled, concluded that, 'Very few coloured or black old people are living in homes for the elderly' ${ }^{86}$ Evidence, again from Haringey, showed that in 1981 only 9 out of $7^{2}$ places in residential homes in the borough were occupied by minority elders. ${ }^{87}$ Problems of diet, language and culture and social isolation are the main factors deterring elderly Asians from using routine residential accommodation.

Meals-on-wheels is another service from which the Asian elderly appear to derive little benefit. Kippax found no antipathy to the idea of meals-on-wheels among his mainly West Indian respondents, but none was in receipt of it in $1974 .{ }^{88} \mathrm{~A}$ number of local authorities have considered a specialist service, but action has been sparse. However, the London Borough of Brent does now provide home meals acceptable to the minority elderly, for example. ${ }^{89}$ The AFFOR study found that almost none of the Asians were attending a day centre and none was receiving meals-on-wheels or the home help service. Yet $37 \%$ of the Asians said they would attend a day centre at a religious centre. ${ }^{90}$ Indeed, the activity patterns of the Asian elders appeared to predispose them to use day centres if they were available. Eighty-three per cent of the Asian men went out of their homes daily, though only $35 \%$ of the women. ${ }^{91}$ Provision is gradually increasing through self-help groups with local authority assistance, though it is still small-scale. ${ }^{92}$

\section{Relationship with Health Services}

With often poor English and low level of contact with British institutions, dealings between the National Health Service and elderly Asians will tend to be more problematic than in the case of the rest of the Asian population. Changes in climate, environment and diet, exposure to transmissible diseases, communication difficulties and unfamiliarity 
with concepts like rehabilitation and preventive medicine, are commonly discussed because of their supposed effect on health and use of services, but there has been little proper research. ${ }^{93}$ Less well-known phenomena such as the use of traditional medicine may reduce the effectiveness and relevance of Western-style health services. Davis and Aslam have shown in their research on the Hakim or traditional healer that Asian patients tend to employ a dual approach to treatment, often consulting both Hakim and Western-trained general practitioners for the same condition. ${ }^{94,95}$ It is reasonable to suppose that the elderly and middle aged are most likely to use these traditional sources of care, through their attachment to older ways and their relative unfamiliarity with allopathic medicine.

Despite the attractiveness of traditional methods, elderly Asians would appear to be making extensive use of the NHS. In the AFFOR study $70 \%$ of the Asians reported seeing their doctor in the previous month, while only $57 \%$ of the whites claimed to have done so. Men and women were equally likely to have visited their doctor. Asians used the hospital service almost as much as whites despite the more youthful age structure of the Asian sample. Of those hospitalised in the previous year, $95 \%$ reported that they had been cared for after discharge by their families. Interestingly, none had received any help from community services. Though cultural attitudes to health and medical services may play a part in these results, objectively higher levels of disease in the Asian elderly cannot be excluded, due to factors such as poorer levels of health in less developed countries, dietary adjustment, poor living and working conditions, anxiety, loneliness and cultural dislocation. ${ }^{96}$ From the AFFOR study it would appear that the ethnic elderly were not significantly healthier than the white respondents who were markedly older.

The subject of mental illness among ethnic minorities already possesses a significant literature although none of it specifically on the Asian elderly in Britain. For example, Lin et al. studying oriental minorities in Canada found that supportive ethnic communities tolerated mental disorder at home as long as there was no disruptive behaviour, at which the help of professional agencies was invoked and the victim was liable to rejection by family. ${ }^{97}$ High tolerance early on may be related to family loyalty (such as one might find in Asian families) but it may also be due to the stigma attached to psychiatric problems by the Chinese who have traditionally regarded mental illness as a punishment for wrongdoing. Similar social and cultural pressures along with limited knowledge of the help available may deter help-seeking in a comparable way among Asian families in Britain.

One final topic relating to health services on which some research has 
been carried out is compliance in medication. Aslam, Davis and Fletcher showed that illiteracy and poor comprehension of English, something to which the elderly are particularly subject, in addition to an unfamiliarity with Western medicine, led to misuse of medication among Asian patients in Birmingham. ${ }^{98}$

There are numerous other important untackled themes to be pursued relating to elderly Asians and health services, such as their pattern of use of hospital services, patterns of morbidity, treatment preferences (e.g. injections versus tablets), expectations of health care and their use of private medicine.

\section{Service Initiatives}

Despite the fragmentary British literature reviewed, it would appear that provision will have to be adapted at a minimum to take account of the broad respects in which the needs of Asian elders differ from those of the white elderly. Vivienne Coombe reminds us that there are precedents for differential residential provision at national level for various national groups such as Poles. ${ }^{99}$

It is likely that two main strands are needed for any successful social policy response to the Asian elderly in Britain.

I. Differential consideration of the cultural differences in ageing problems inherent in membership of different ethnic groups, which affect perceptions of old age and abilities to cope with the problems it brings.

2. Preferential consideration of minority elderly in response to their 'double jeopardy' situation. ${ }^{100}$

The first strand, which considers cultural differences, would appear to be especially important in an assessment of the required content and style of delivery of services and in an understanding of why certain groups are reluctant to admit their need for services in particular cases, other groups in other cases (because of their varying definitions of what are socially acceptable and socially admissible problems) and also why routine majority services are shunned as unsuitable even in times of need. Indeed the background of the second strand of policy relating to discrimination and racial disadvantage has been well documented in a number of British studies. ${ }^{101}$

Generally, however, although the number of health authorities and social services departments aware of the needs of ethnic minority elderly is growing, very few provide or support special services for a variety of reasons. Policy makers have been inhibited by a tendency to think in terms of conventional client groups, ${ }^{102}$ by assumptions that there are 
few elderly ethnic people, that those who have been in Britain a long time are fully 'adapted' and by a general reluctance, until recently, to look at the needs of ethnic minorities at all. ${ }^{103}$

Naomi Connelly's recent study (carried out before the urban riots of the summer of $198 \mathrm{I}$ ) of the response of six local authority Social Services Departments to the presence of substantial numbers of ethnic minority population within their boundaries showed great variation, both between and within Departments; first in the perceived salience of an ethnic dimension to the Department's work; secondly in the interpretation of the exact nature of the ethnic dimension; and thirdly in the degree of involvement in and interest in the modification of services. In general, there was a tendency to look at particular problems as they presented themselves. It was not seen as feasible to develop a strategic approach. Despite the fact that two authorities provided Asian mealson-wheels and this was under consideration in a third, planning provision for the Asian elderly was seen as especially problematic. It was generally felt that the current level of information was inadequate as a basis for action. There were considerable uncertainties expressed about matters such as the likelihood of return migration, the continuing role of the family in care of the elderly and the problem of prejudice from the white elderly, preventing integrated provision. Despite a reluctance to tackle the needs of the elderly, all six Departments had demonstrated incremental changes in their practice in other aspects of their work with ethnic minorities in a range of ways. ${ }^{104}$ It would seem that since the urban riots of $198 \mathrm{I}$ recognition of the needs of ethnic minorities by service providers has become more explicit. Provision for the elderly tends to be through assistance to clubs and self-help groups, rather than direct provision.

As a result of earlier local authority backwardness, black elders have been forming their own groups and voluntary housing schemes have been initiated, most notably in Wandsworth and Brent in London, where the initiative came from the community and help was forthcoming from the local authorities. Work in Haringey, London suggested that sheltered housing, where the Asian elderly could live in a family atmosphere and prepare some of their own food, was preferable to full residential care, unless the elderly suffered severe physical limitation. ${ }^{105}$ The Wandsworth scheme known as ASRA (Asians' Sheltered Residential Accommodation) was a local response to workers' perceptions of the special housing needs of elderly Asians and of the discrimination they faced from private landlords if unable to live with their families. Provision consisted of self-contained flats in an area with a strong Asian community, near Asian shops and places of worship, where support and 
amenities were available. The project dealt not only with people unable to live with their families but also, valuably, it helped forced migrants from countries like Uganda, who were especially vulnerable, often lacking the support of close relatives. ${ }^{106}$ The ASRA scheme in Wandsworth has been followed by a similar development in Leicester where an ASR A committee was established in 1980 . However, despite Brent, Wandsworth and Leicester, it would seem likely that there is a need for this type of provision elsewhere and that this need will persist into the future. Zuzana Hughes found that mid-European migrants of long standing in Britain were strongly attached in old age to traditional lifestyles and desired to enter old people's homes catering for their own ethnic group. ${ }^{107}$

Reva Klein describes three other self-help groups of minority elderly in London ${ }^{108,109}$ and explains that Asian elderly can find themselves left out of the social activities and facilities enjoyed by whites, either through language problems, cultural differences, or feelings of unease in the presence of whites, or even because of open hostility. The Asian elderly's need for activities to occupy their time and for a place to go outside their homes may be acute, especially where households are large. Vivienne Coombe sees day facilities as one of the key areas for improving the lives of elderly black people. ${ }^{110}$ However, the innovations described by Klein are not the norm. Nevertheless, there were probably thirteen clubs for elderly Asians in Greater London by I $98 \mathrm{I}$, providing food, activities and welfare rights information. ${ }^{111}$ None was run directly by local authorities but seven received local authority funds.

The provision of separate old people's homes is a much more sensitive issue than day centres, meals, or sheltered housing and presents logistical problems, given the diversity of lifestyles to be catered for, depending on nationality, area of origin, age, sex, religion and language. Separate provision is only likely to be viable where concentrations of a similar minority sub-group exist.

Finally in this section, as a reflection of the growing interest of health authorities and local government in the needs of elderly members of ethnic minorities, a number of authorities have recently reviewed their policies for these groups and identified key services such as mealson-wheels, lunch clubs, housing, civic amenities and day care. ${ }^{112-114}$ In addition, discussions of appropriate responses have begun to appear in the social work literature in widely available form. ${ }^{115}$ From these sources it is possible to assemble a variety of the policy recommendations addressed to Social Services Departments and others, to give an indication of the scope for possible, future innovations in this field.

I. Local authorities should make better use of Section I 1 of the 1966 
Local Government Act to fund salaries in housing and social services of staff working with New Commonwealth groups.

2. Local authorities are reminded of their special requirement to provide assistance, finance and training to deprived racial groups under Secton 7 I of the 1976 Race Relations Act.

3. Local authorities and health authorities should select and train suitable staff as home helps, residential care staff, district nurses and health visitors.

4. Local authorities should consider helping ethnic self-help projects, including residential accommodation in suitable areas, and should develop links with religious organisations of significance to the elders.

5. Culturally acceptable meals should be provided as routine practice.

6. Better processes of dissemination should be set up so that providers can learn from others' experiences in meeting the needs of the ethnic elderly. ${ }^{116}$

\section{Ageing and modernisation - the importance of culture}

An aspect of the position of Asian elders which has not been discussed because there is no British literature is the likely impact on their status and esteem of the transition to a mature Western, industrialised society and of witnessing an unaccustomed attitude to old age. It is obviously important to the study of a group such as elderly Asians from societies said traditionally to have assigned high status to older people, to see how their situation will have changed both objectively and in their own estimation on coming to Britain. For it is popularly asserted that a modern society devalues the aged and that in less modernised societies the aged have higher status with roles in the family and economy. ${ }^{117}$ However, the evidence is not so unanimous ${ }^{118-121}$. It suggests that the position of the elderly in the past in different societies in East and West has varied considerably. ${ }^{122}$ Harlan went so far, for example, as to say that the 'precarious' position of the aged in the Indian pre-industrial communities which he studied was inherent in traditional life in India and understandable apart from consideration of urbanisation and industrialisation. ${ }^{123}$ Other studies in India have found modernisation undermining the status of elders. ${ }^{124}$ The diversity of the conclusions reflects in part differing definitions of the mutli-faceted phenomenon of status, the great diversity and size of India and the fact that studies of Indian society in the last thirty years provide no more than 'snapshots' from which generalisation is risky (for example, ${ }^{125-127}$ ). It can, for instance, be argued that in material terms the most advanced societies, 
with welfare services, assist people to fulfil their obligations to their elderly and to provide them with a higher standard of living. Japan provides good evidence that the effects of modernisation on the status of older people depend on the cultural context. The Japanese tradition of respect for elders appears to have prevented the expected major decline in status of the aged with industrialisation. ${ }^{128}$ Indeed, it would appear that most families in India today fall in the middle of a continuum between the traditional joint family, associated with high status for the elderly and the nuclear family. ${ }^{129}$

In sum, it would seem that the changes accompanying modernisation may undercut the position of the elderly, especially in the early stages, but that the impact is less clearcut and less uniform than popularly thought. The content and significance of ethno-religious traditions supportive of elders and their durability in a modern, Western context are thus important in shaping the lives of Asian elders in Britain, in addition to structural features of a modern society.

\section{Disengagement Theory}

Study of elderly Asians may have a bearing on both 'activity' and 'disengagement' theories in gerontology. ${ }^{130}$ Comparative studies of the levels of activity of Asian and white elderly and of their life satisfaction in Britain would add to knowledge of the varying relation between levels of activity and 'successful' ageing in different cultural contexts, and would indicate the extent to which 'disengagement' is determined by the culture and society, rather than by inevitable processes of senescence. Palmore's study of the relationship between disengagement and successful ageing in Japan and Western nations showed that the level of disengagement appeared to be closely related to cultural norms and expectations. Thus, it was less common in Japan, where elders are traditionally respected and treated with consideration. ${ }^{131}$

From the perspective of the 'disengagement' versus 'activity' theory debate the Áśramas, the ideal scheme of the Hindu life-cycle, and Asian interpretations of it in practice, do appear superficially to be a form of institutionalised prescription for healthy ageing via disengagement, since the last two stages tend to be less directly involved in the affairs of the material world and concentrate more on spirituality and preparation for the ultimate goal of life. ${ }^{132}$ However, it is not a withdrawal associated with a loss of status and emptying of roles (as Cumming and Henry describe disengagement), ${ }^{133}$ but a replacement of certain socially valued, material roles by others, including spiritual roles. However, it remains to be seen through research whether such traditions (possibly 
revived in the minority context), will persist and maintain the integration and recognition of Hindu elders in Britain.

A recent study of ageing and disengagement in India by Vatuk ${ }^{134}$ concluded that the influence of the ideal of withdrawal in later life was still apparent in Hindus, but that, although a degree of social and psychological retreat took place, it did not mean a total cessation of social activity. The existence of a normative prescription for a form of withdrawal from material power enabled older people to give in gracefully to younger people and to avoid direct inter-generational conflict. At the same time this withdrawal did not imply social inactivity, though the elderly did not generally exercise authority or manage affairs.

The evidence is not yet available to be able to say whether or not the power struggle between the generations will be more naked in the British context. Much depends on how strongly and commonly held by young and old the traditional normative prescriptions for old age remain. For it would appear that where the different generations share similar expectations of age-appropriate behaviour, there is a greater opportunity for old people to cope with the changed self-image and loss of esteem associated with transition to old age status. ${ }^{135}$

\section{Conclusion}

Discussion of elderly Asians in Britain has tended to rest on a range of sometimes contrary assumptions. This literature review has tried tentatively to show the frailty of these assumptions, the extent of our ignorance, the need for research and the lessons of research from outside Britain. Two typical assumptions which have coloured thinking in this field, for instance, have been as follows.

I. Asian culture and family life will continue to support the elderly without the need for welfare services

and, in contrast,

2. Migration to Britain will erode the traditional practices and values supportive of the elderly.

In the light of this review, perhaps both would be better replaced by questions as follows.

(i) How are Asian family patterns changing?

(ii) What are the attitudes of younger people to their elders and how are inter-generational relations changing?

(iii) How do Asian elders conceptualise old age and how are their conceptualisations changing in the light of circumstance? 
(iv) What is the extent of neglect among the elderly, especially those without close relatives in Britain?

(v) Today's and tomorrow's Asian elders came to Britain from different parts of the world, at different times and in response to a variety of 'push' and 'pull' factors; how do the lifestyles of these groups differ?

Despite evidence of their vulnerability, there has been a reluctance in Britain, until recently, to act to improve access and use of health and social services by the minority elderly. However, it is beginning to be made clearer that the essence of a sensitive welfare system is its ability to discriminate fairly between categories of need, even if these coincide with ethnic group divisions. ${ }^{\mathbf{1 3 6}}$

Jo Cooper stresses that there are two tasks in providing effective services to the ethnic elderly: first, existing welfare systems should be made more sensitive. But this is insufficient alone, she contends. 'By defining and interpreting the needs of any group in terms of existing services, and seeking their solutions in modifications to these services, some needs might be overlooked or more relevant methods of meeting needs might not be found. An alternative is to identify needs as defined by the elderly...themselves, and then to consider all possible ways of meeting them, which may not always be through existing services. ${ }^{137}$ However, innovation is called for, not just on grounds of full and efficient need detection, but also for the sake of social justice: 'It can be argued that if...policy is geared to the needs of English elderly persons then other elderly persons would only be treated equally if their needs were the same as those of the English - if their needs were different it is likely that they would be at a disadvantage in that they would not be catered for in the same way.' ${ }^{138}$

If usable and relevant services could be provided, then the invaluable traditional respect and sense of responsibility for the elders which still appear to exist in Asian communities could be capitalised on and nurtured. It will not be easy because of the great diversity which exists within the Asian elderly as the Age Concern study shows and which most providers are still unaware of. Providers will also have to acknowledge and resolve the thorny question of whether direct provision or support for a voluntary group is the more effective or responsible way to respond to the needs of the Asian elderly.

\section{NOTES}

I Kippax, C. A step into the unknown: a study of elderly New Commonwealth immigrants resident in the Borough of Lewisham. Age Concern Lewisham, London, 1978.

2 Pyke-Lees, C. and Gardiner, S. Elderly ethnic minorities. Age Concern Manifesto Series, No. 18: Specialist Report. Age Concern England, London, 1974. 
3 Glendenning, F. Another turn of the screw, New Age, to (1980), 27-29. Reprinted in J. Cheetham, W. James, M. Loney, B. Mayor and W. Prescott, eds., Social and Community Work in a Multi-racial Society: a Reader. Harper and Row/Open University, London, $198 \mathrm{I}, 225^{-23} \mathrm{I}$.

4 Coombe, V. Britain's other elderly: racial discrimination and the coloured elderly. New Age, 8 (1978), 9-1 I. Reprinted in Cheetham et al., Social and Community Work...218-224.

5 Blakemore, K. and Bhalla, A. 'The elderly of ethnic minorities: a review of the literature and news of a research project in Birmingham.' Unpublished paper, All Faiths for One Race, Birmingham, I979, I.

6 AFFOR. Elders of the Minority Ethnic Groups. All Faiths For One Race, Birmingham, I $98 \mathrm{I}$.

7 Berry, S., Lee, M. and Griffiths, S. Report on a Survey of West Indian Pensioners in Nottingham. Nottinghamshire County Council, Social Services Department, Research Section, Nottingham, ig8 .

8 Barker, J. Black and Asian old people in Britain. Research Perspectives on Ageing, Report No. 1, Age Concern England, London, I982 (in press).

9 Bland, J. British Elderly Ethnic Minorities. NISW one-year course of Further Studies I 978/9, Social Policy Sequence, Term 3. Paper for discussion on 9 May 1979 (unpublished draft). National Institute for Social Work, London, 1979, I.

Io Hannon, P. Old people in ethnic minorities. Liberator, no. I08 (I980), I3-18.

I I Cowgill, D. O. and Holmes, L. D., eds., Aging and Modernization. AppletonCentury-Crofts, New York, I972.

12 See for example, Dowd, J. J. and Bengtson, V. L., Aging in minority populations: an examination of the double jeopardy hypothesis. Journal of Gerontology, 33 (1978), 427-436.

13 Dahya, B. Pakistanis in England. New Community, 2 (1972), 25-34.

14 Dahya, B. Pakistanis in Britain: transients or settlers? Race, 14 (1973), 241-277.

I5 Wiehl, H. Selected aspects of aging in Israel, 1969. In D. O. Cowgill and L. D. Holmes, eds., op. cit. I97-209.

16 Kiefer, C. Lessons from the Issei. In J. Gubrium, ed., Late Life: Communities and Environmental Policies. Charles C. Thomas, Springfield, Illinois, 1974, 167-197.

I7 Carp, F. and Kataoka, E. Health care problems of the elderly of San Francisco's Chinatown. Gerontologist, 16 (1976), 30-38.

18 Jackson, J. J. Compensatory care for the black aged. In Minority Aged in America. Occasional Paper No. Io, Institute of Gerontology, University of MichiganWayne State University, Ann Arbor, Mich., 1971, 15-23.

19 Jackson, J. J. Aged Negroes: their cultural departures from statistical stereotypes and rural-urban differences. Gerontologist, 10 (1970), I $40-145$.

20 Cowgill, D. O. and Holmes, L. D., eds., op. cit.

2 I Dowd, J. J. and Bengtson, V. L. op. cit.

22 Ward, R. A. The Aging Experience: an Introduction to Social Gerontology. J. B. Lippincott Co., New York, 1979, 59.

23 Hill, R. A profile of black aged. In Minority Aged in America, 35-50.

24 Wylie, F. Attitudes toward aging and the aged among black Americans: some historical perspectives. Aging and Human Development, 2 (1971), 66-70.

25 Carp, F. and Kataoka, E. op. cit.

26 Jackson, J. J. op. cit. 1970.

27 Dowd, J. J. and Bengtson, V. L. op. cit.

28 Carp, F. Factors in utilization of services by the Mexican American elderly. American Institutes for Research, Palo Alto, Calif., 1968. Cited in Moore, J. W., MexicanAmericans. Gerontologist, 11 (1971), 30-35.

29 Reich, J. M., Stegman, M. A. and Stegman, N. W. Relocating the Dispossessed 
Elderly: a Study of Mexican Americans. University of Pennsylvania, Institute for Environmental Studies, Philadelphia, I966. Cited in Moore, J. W. MexicanAmericans. Gerontologisl, I I (1971), 30-35.

30 Kiefer, C. W. Notes on anthropology and the minority elderly. Gerontologist, 2 (I 971 ) , 94-98.

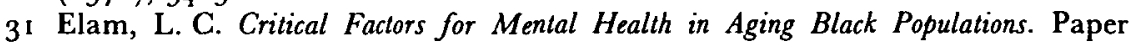
delivered at the workshop on Ethnicity, Mental Health and Aging. Los Angeles, Calif., April 1970. Cited in Moore, J. W., Situational factors affecting minority aging. Gerontologist, I I ( $197 \mathrm{r}), 88-93$.

32 Moore, J. W. Mexican-Americans. Gerontologist, 1 I (1971), 30-35.

33 Williams, G. C. Warriors no more: a study of the American Indian elderly. In C. L. Fry, ed. Aging in culture and society. J. F. Bergin Publishers, New York, I 980, I0I-I25.

34 Moore, J. W. Mexican-Americans. Gerontologist, 11 (1971), 30-35.

35 Pyke-Lees, C. and Gardiner, S. op. att. I am indebted to Ken Blakemore and Anil Bhalla's unpublished paper (The elderly of ethnic minorities: a review of the literature and news of a research project in Burmingham. AFFOR, Birmingham, 1979) and to Naomi Connelly of the Policy Studies Institute, London, for some of the more obscure bibliographical leads followed in this section.

$3^{6}$ Central Statistical Office. Social Trends, 9 (1979), Table 3.19, 69, HMSO, London.

37 Ibid.

$3^{8}$ Central Statistical Office. Social Trends, 9 (1979), Table 3.21, 70, HMSO, London.

39 Central Statistical Office. Social Trends, 10 (1980), Table 1.18, 104, HMSO, London.

40 Central Statistical Office, loc. cit. I979, Table 3.19, 69 .

4I Birmingham Community Relations Council. 'Housing and elderly ethnic minorities: a report to the CRC Housing Panel', by $\mathrm{H}$. Hodgins and $\mathrm{A}$. Bhalla. Unpublished paper. Birmingham CRC, Birmingham, March 1979.

42 Commission for Racial Equality (CRE). Multi-racial Britain: the Social Services' Response-a Working Party Report. Commission for Racial Equality, London, 1978, 49-50.

43 Connelly, N. Social Services Provision in Multi-racial Areas. Research Paper 8I/4, Policy Studies Institute, London, I98I, 53.

44 Kippax, C. op. cit.

45 Elders of the Minority Ethnic Groups. All Faiths For One Race, Birmingham, 1981, 32.

46 Lawrence, D. Black Migrants: White Natives - a Study of Race Relations in Nottingham.

Cambridge University Press, Cambridge, r 974, 27-39.

47 Hannon, P. loc. cit. (n. 10), 14-15.

48 Blakemore, K. and Bhalla, A. op. cit. (n. 5), 3 .

49 Chowdhury, A. 'Housing and elderly ethnic minorities.' Unpublished paper prepared for a liaison meeting of Birmingham Housing Department with Birmingham Community Relations Council, 2 I July I980. Birmingham Housing Department, I 980, 2.

5o Kippax, C. op. cit.

51 Cooper, J. M. Elderly West Indians in Leicester. Unpublished dissertation for University of Essex, Department of Sociology, M.A. in Social Service Planning $1976 / 77$.

52 AFFOR, op. cit.

53 Berry, S., Lee, M. and Griffiths, S. op. cit.

54 AFFOR, op. cit. 18-19. 
55 Cooper, J. M. op. cit. 67.

56 Community Relations Commission (CRC). Between two cultures: a study of relationships between generations in the Asian community in Britain. Community Relations Commission, London, 1976, I8-19.

57 Ballard, C. Conflict, continuity and change: second generation South Asians. In V. Saifullah Khan, ed., Minority Families in Britain: Support and Stress. SSRC/ Macmillan, London, 1979, I26-1 29.

58 AFFOR, op. cit. $15-16$.

59 Berry, S., Lee, M. and Griffiths, S. op. cit. (n. 7), 4.

6o Hunt, A. The Elderly at Home. HMSO, London, 1976.

6. AFFOR, op. cit. 29.

62 Cooper, J. M. op. cit. 1977, 70.

63 AFFOR, op. cit. 28.

64 Ibid. 23.

65 Barker, J. op. cit.

66 Hazan, H. The Limbo People: a Study of the Constitution of the Time Universe among the Aged. Routledge and Kegan Paul, London, 1980.

67 Reported in Community Relations Commission (CRC). Refuge or Home? A Policy Statement on the Resettlement of Refugees. Community Relations Commission, London, 1976, 32-39.

68 Hannon, P. op. cit. 17.

69 Kippax, C. op. cit. section 7, part C.

70 Townsend, P. Poverty in the United Kingdom: a Survey of Household Resources and Standard of Living. Penguin, Harmondsworth, 1979, Table 24. 2, 828.

$7 \mathrm{I}$ Glendenning, F. The elders in ethnic minorities in the U.K. In F. Glendenning, ed., The Elders in Ethnic Minorities. Beth Johnson Foundation, in association with the Department of Adult Education, University of Keele and the Commission for Racial Equality, Stoke-on-Trent, 1979, 54-6I.

72 Ibid.

73 AFFOR, op. cil. 18.

74 Mooneeram, R. The Asian elders. In F. Glendenning, ed., op. cit. 50-53.

75 For example, Hannon, P. op. cit.

76 Chowdhury, A. op. cit. 4.

77 Pyke-Lees, L. and Gardiner, S. op. cil.

78 Smith, D. Racial Disadvantage in Britain. Penguin, Harmondsworth, 1977, 46-47.

79 Hannon, P. op. cit. I5.

80 Smith, D. op. cit. 213.

81 Haringey Community Relations Council. The ethnic elderly-Asians, Cypriots, West Indians, Haringey CRC, London, 1978. Cited in $\mathrm{K}$. Blakemore and A. Bhalla, op. cit. 6.

82 London Borough of Haringey. The Minority Ethnic Elderly and Their Needs. Report of the Ethnic Elderly Working Party of the Ethnic Minorities Joint Consultative Committee. London Borough of Haringey, London, $198 \mathrm{I}$ (duplicated).

83 Quoted in Hannon, P. op. cit. 16.

84 AFFOR, op. cit.

85 Kippax, C. op. cit. section 7, part B.

86 Pyke-Lees, C. and Gardiner, S. op. cit. appendix C, 17.

87 London Borough of Haringey. op. cit.

88 Kippax, C. op. cit. section 7, part C.

89 Harding, T. A Review of Council Services as they Affect Elderly People. Project Report No. 2, Chief Executive's Office, London Borough of Brent, London, 1981, 37-42 (duplicated).

9o AFFOR, op. cil. 27-29. 
9 I lbid. I9-20.

92 Hanson, J. Clubs and Day Centres in London for the Asian Elderly. Asian Community Action Group/Age Concern Greater London, London, 198 I.

93 Henley, A. Asian Patients in Hospital and at Home. King Edward's Hospital Fund for London, London, 1979.

94 Davis, S. S. and Aslam, M. 'The Hakim and his role in the immigrant community.' University of Nottingham, Department of Pharmacy. Unpublished paper. No date [ 1980 ?].

95 Aslam, M. and Davis, S. S. The role of the traditional practitioner with an Asian community in the United Kingdom. Social Science and Medicine (forthcoming).

96 Blakemore, $\mathrm{K}$. Health and illness among the elderly of minority ethnic groups living in Birmingham: some new findings. Health Trends, 14, 3 (1982), 69-72.

97 Lin, T. Y., Tardiff, K., Donetz, G. and Goresky, W. Ethnicity and patterns of help-seeking. Culture, Medicne and Psychiatry, 2(1978), 3-13.

98 Aslam, M., Davis, S. S. and Fletcher, R. Compliance in medication by Asian immigrants. Nursing Times, 75 (1979), 931-932.

99 Coombe, V. op. cit. I I.

I oo McCaslin, R. and Calvert, W. R. Social indicators in black and white: some ethnic considerations in delivery of service to the elderly. Journal of Gerontology, 30 (1975), 6o-66.

IoI For example, Smith, D. op. cit.

I 02 Glendenning, F. Ethnic minority elderly people: some issues of social policy. In J. Cheetham, ed., Social Work and Ethnicity. George Allen and Unwin, London, I 982, I $22-132$.

I 03 Connelly, N. 'Elderly people from ethnic minorities: information and issues for social services.' Unpublished paper to British Society of Gerontology Annual Conference, Exeter, September, 1982.

104 Connelly, N. op. cit. $198 \mathrm{I}$.

I05 Haringey Community Relations Council, op. cit.

I06 Asian Community Action Group. Report on Asians' Sheltered Residential Accommodation $(A S R A)$. Asian Community Action Group, London, I980.

107 Hughes, Z. How to be an ancient Briton. New Age (Summer 1979), I2-13.

Io8 Klein, R. On the upbeat. Help Age International (October 1978), 8.

rog Klein, R. The old blacks beat the blues. Community Care, 24 (4 Jan. 1979), I8-i 9.

I Io Coombe, V. Social work with ethnic minority elderly people. In J. Cheetham, ed., op. cit. (n. I02), 133-142.

I I Hanson, J. op. cit.

I 2 Harding, T. op.cit.

113 Haringey Community Relations Council, op. cit.

I 4 London Borough of Haringey, op. cit.

I 5 Glendenning, F. and Coombe, V. op. cit. in J. Cheetham, ed.

It 6 From the following, cited as shown: Hanson, J., n. 92; Glendenning, F., n. I02; Coombe, V., n. I Io; and Connelly, N., n. 43.

I 7 Laslett, P. Societal development and aging. In R. H. Binstock and Ethel Shanas, eds., Handbook of Aging and the Social Sciences. Van Nostrand Reinhold, New York, $1976,87-116$.

I 8 Cowgill, D. O. and Holmes, L. D. eds., op. cit.

119 Cowgill, D. O. Aging and modernization: a revision of the theory. In J.F. Gubrium, ed., op. cit. (n. 16), 123-146.

I 20 Palmore, E. and Whittington, F. Trends in the relative status of the aged. Social Forces, 50 (1971), 84-91. 
I 1 Palmore, E. B. and Manton, K. Modernization and status of the aged: international correlations. Journal of Gerontology, 29 (1974), 205-210.

122 Laslett, P. and Wall, R., eds. Household and Family in Past Time. Cambridge University Press, Cambridge, 1972.

123 Harlan, W. H. Social status of the aged in three Indian villages. Vita Humana, $7\left(19^{6} 4\right), 239^{-252 .}$

124 Rowe, W. L. The middle and later years in Indian society. In R. W. Kleemeier, ed., Aging and Leisure. Oxford University Press, New York, 196 I, I04-109.

I 25 Dube, S. C. Indian Village. Routledge and Kegan Paul, London, 1955.

126 Marriott, M., ed. Village India, University of Chicago Press, Chicago, 1955.

127 Beals, A. R. Gopalpur: a South Indian Village. Holt Rinehart and Winston, New York, 1963 .

128 Palmore, E. op. cit. 4 .

129 Ramanujam, B. K. The Indian family in transition. In The Indian Family in the Change and Challenge of the Seventies (selected papers of a seminar organised by the Family Life Centre of the Indian Social Institute, New Delhi). Sterling, New Delhi, 1972, 22-34.

r 30 Cumming, E. and Henry, W. E. Growing Old. Basic Books, New York. 1961.

I 3 I Palmore, E. op. ctt.

I 32 Kapadia, K. M. Marriage and Family in India. Oxford University Press, Bombay, third edition, $1966,24-37$.

133 Cumming, E. and Henry W. E. op. cit. $210-218$.

134 Vatuk, S. Withdrawal and disengagement as a cultural response to aging in India. In C. L. Fry, ed., op. cit. I $26-148$.

I 35 Kagan, D. Activity and aging in a Columbian peasant village. In C. L. Fry, ed., op. cit. $65-79$.

I 36 Cross, C. Ethnic Minorities in the Inner City. Commission for Racial Equality, London, 1978.

137 Cooper, J. West Indians in Leicester: a case study. In F. Glendenning, ed., op. cit. (n. $7 \mathrm{I}), 4^{\mathrm{I}}$. Extracts reprinted in Cheetham et al., op. cit. (n. 3), 232-242.

138 Cooper, J. M. op. cit. $1977,116$. 